\title{
Characteristics and clinical relevance of postgastrectomy syndrome assessment scale (PGSAS)-45: newly developed integrated questionnaires for assessment of living status and quality of life in postgastrectomy patients
}

\author{
Koji Nakada $\cdot$ Masami Ikeda $\cdot$ Masazumi Takahashi $\cdot$ Shinichi Kinami $\cdot$ Masashi Yoshida \\ Yoshikazu Uenosono • Yoshiyuki Kawashima • Atsushi Oshio · Yoshimi Suzukamo • \\ Masanori Terashima $\cdot$ Yasuhiro Kodera
}

Received: 3 September 2013/Accepted: 13 January 2014/Published online: 11 February 2014

(c) The International Gastric Cancer Association and The Japanese Gastric Cancer Association 2014

\begin{abstract}
Background Lack of a suitable instrument to comprehensively assess symptoms, living status, and quality of life in postgastrectomy patients prompted the authors to develop postgastrectomy syndrome assessment scale (PGSAS)-45.

Methods PGSAS-45 consists of 45 items in total: 8 items from SF-8, 15 items from GSRS, and an additional 22 items selected by 47 gastric surgeons. Using the PGSAS-45, a multi-institutional survey was conducted to determine the prevalence of postgastrectomy syndrome and its impact on everyday life among patients who underwent various types of gastrectomy. Eligible data were obtained from 2,368 patients
\end{abstract}

For the Japan Postgastrectomy Syndrome Working Party.

\section{K. Nakada ( $₫)$}

Department of Surgery, The Jikei University School of

Medicine, 3-25-8, Nishishimbashi, Minato-ku, Tokyo 105-8461,

Japan

e-mail: nakada@jikei.ac.jp

\section{Ikeda}

Department of Surgery, Asama General Hospital, Saku, Japan

\section{Takahashi}

Division of Gastroenterological Surgery, Yokohama Municipal Citizen's Hospital, Yokohama, Japan

\section{S. Kinami}

Department of Surgical Oncology, Kanazawa Medical School,

Kanazawa, Japan

\section{Yoshida}

Surgery and Digestive Diseases Center, International University of Health and Welfare, Mita Hospital, Tokyo, Japan

Y. Uenosono

Department of Digestive Surgery, Kagoshima University

Graduate School of Medicine, Kagoshima, Japan operated and followed at 52 institutions in Japan. Of these, data from 1,777 patients were used in the current study in which symptom subscales of the PGSAS-45 were determined. We also considered the characteristics of the postgastrectomy syndrome and to what extent these symptoms influence patients' living status and quality of life (QOL).

Results By factor analysis, 23 symptom-related items of PGSAS-45 were successfully clustered into seven symptom subscales that represent esophageal reflux, abdominal pain, meal-related distress, indigestion, diarrhea, constipation, and dumping. These seven symptom subscales and two other subscales measuring quality of ingestion and dissatisfaction for daily life, respectively, had good internal consistency in terms of Cronbach's $\alpha(0.65-0.88)$.

\section{Y. Kawashima}

Division of Gastroenterological Surgery, Saitama Cancer Center,

Saitama, Japan

A. Oshio

Faculty of Letters, Arts and Sciences, Waseda University,

Tokyo, Japan

Y. Suzukamo

Department of Physical Medicine and Rehabilitation, Tohoku

University Graduate School of Medicine, Sendai, Japan

M. Terashima

Division of Gastric Surgery, Shizuoka Cancer Center, Shizuoka, Japan

\section{Y. Kodera}

Department of Gastroenterological Surgery, Nagoya University Graduate School of Medicine, Nagoya, Japan 
Conclusion PGSAS-45 provides a valid and reliable integrated index for evaluation of symptoms, living status, and QOL in gastrectomized patients.

Keywords Postgastrectomy syndrome - Questionnaires · Quality of life · Gastrectomy

\section{Introduction}

Postgastrectomy syndrome (PGS) remains a serious drawback for gastric cancer survivors after gastrectomy [1-6]. PGS includes numerous symptoms related to the loss of the stomach, leading to impairments in living status and quality of life (QOL). Several surgical procedures have been sought to maintain or even to reconstruct the gastric functions through preservation of nerves and other anatomical structures and through sophistication in the method of reconstruction [7, 8]. Hard data showing benefits of various considerations in surgical procedure have been scarce, however, partly because of the lack of adequate endpoints when these procedures are evaluated in clinical trials. It is important, therefore, to be able to weigh the intensity of the various symptoms that emerge after gastrectomy and elucidate to what extent they affect the patients. If an appropriate instrument is available, we shall be able to identify which surgical procedure can be helpful in preventing or ameliorating PGS. Evidence-based knowledge in this area of interest is mandatory for adequate selection of surgical procedure, especially at reconstruction.

To establish an adequate instrument to measure the incidence and relevance of the PGS in terms of patientreported outcome, the Japanese Postgastrectomy Syndrome Working Party led by the authors designed and constructed a new integrated questionnaire, the Postgastrectomy Syndrome Assessment Scale (PGSAS)-45, to specifically assess symptoms, living status, and QOL of the patients who underwent gastrectomy. A nationwide multi-institutional study was then undertaken to validate the PGSAS-45 and to survey the incidence and intensity of the PGS observed after various surgical procedures.

Standard procedures for scale development in medical research and practice were used to construct a valid, reliable, and clinically useful scale for the assessment of PGS. In the current article, this challenging process is described with particular emphasis on the selection and aggregation of the list of symptoms. The structure and characteristics of the final version of PGSAS-45 were then disclosed. Through findings from a clinical study to validate the PGSAS-45, characteristics of PGS among postgastrectomy patients were summarized, and the influence of the symptoms on the QOL and living status of the patients was identified.

\section{Patients and methods}

The Japanese Postgastrectomy Syndrome Working Party

The Japanese Postgastrectomy Syndrome Working Party (JPGSWP), established in 2006, is a voluntary organization of surgeons whose aims were (1) to construct a standardized instrument to evaluate PGS and (2) to use the instrument to identify the optimal surgical procedure that minimizes impairment of QOL among patients who undergo gastrectomy. The JPGSWP has grown during the process and currently consists of 212 surgeons and 52 other medical staff persons (pharmacologists, nurses, and nutritionists) from various Japanese institutions. The first task undertaken by the JPGSWP, thus, was to construct the PGSAS-45.

\section{Development of a new questionnaire, PGSAS-45}

PGSAS-45 was designed to comprehensively characterize and evaluate symptoms, living status, and QOL of patients who underwent gastrectomy (Table 1). It was expected to provide a realistic image of the status of the patients and to be regarded as a gold standard in surveillance of the PGS and evaluation of various types of gastrectomy and reconstruction.

First, a comprehensive item pool or list of items representing symptoms and functions was generated. For this purpose, data on PGS were collected from a variety of sources such as published articles and abstracts of domestic surgical meetings. In addition, symptoms that were actually claimed to have been the cause of annoyance for the patients or considered to have affected their everyday lives were retrieved through scrutiny of an earlier questionnaire survey from 252 patients who underwent gastrectomy and by direct interview with 117 patients. This comprehensive and potentially over-inclusive list of items and symptoms was then reviewed to determine which items should be retained. To do so, the list was dispatched by mail to 51 members of the JPGSWP who were asked to arrange the items in the order of clinical importance. Although the items related to issues of significant clinical importance were not to be deleted (all items that were considered by more than $50 \%$ of the surgeons as clinically relevant were to be retained), the total number of items was expected to be within 50. Forty-seven of the 51 surgeons (92\%) eventually responded and met at a consensus meeting in March 2007 to discuss which items should eventually be retained to construct the PGSAS- 45 .

Further discussion among the JPGSWP members and interviews with the experts in QOL evaluation (Y.S.) were carried out and, through empirical verification, items that 
Table 1 Structure of postgastrectomy syndrome assessment scale (PGSAS)-45 (domains/subdomains/items/subscales)

\begin{tabular}{|c|c|c|c|c|c|}
\hline \multirow{2}{*}{ Domains } & \multirow{2}{*}{$\begin{array}{l}\text { Subdomains } \\
\text { SF-8 }\end{array}$} & \multicolumn{3}{|c|}{ Items } & \multirow{2}{*}{$\begin{array}{l}\text { Subscales } \\
\text { Physical component summary* }\end{array}$} \\
\hline & & 1 & Physical functioning* & Five- or six-point & \\
\hline & & 2 & Role physical* & & Mental component summary* \\
\hline & & 3 & Bodily pain* & & \\
\hline & & 4 & General health* & & \\
\hline & & 5 & Vitality* & & \\
\hline & & 6 & Social functioning* & & \\
\hline & & 7 & Role emotional* & & \\
\hline & & 8 & Mental health* & & \\
\hline \multirow[t]{25}{*}{ Symptoms } & \multirow{15}{*}{$\begin{array}{l}\text { Gastrointestinal } \\
\text { Symptom } \\
\text { Rating } \\
\text { Scale (GSRS) } \\
\text { items }\end{array}$} & 9 & Abdominal pains & \multirow{25}{*}{$\begin{array}{l}\text { Seven-point Likert } \\
\text { scale } \\
\text { except items } 29 \\
\text { and } 32\end{array}$} & $\begin{array}{l}\text { Esophageal reflux subscale (items } 10,11 \text {, } \\
13,24 \text { ) }\end{array}$ \\
\hline & & 10 & Heartburn & & Abdominal pain subscale (items $9,12,28$ ) \\
\hline & & 11 & Acid regurgitation & & $\begin{array}{l}\text { Meal-related distress subscale (items } \\
25-27 \text { ) }\end{array}$ \\
\hline & & 12 & Sucking sensations in the epigastrium & & Indigestion subscale (items 14-17) \\
\hline & & 13 & Nausea and vomiting & & Diarrhea subscale (items 19, 20, 22) \\
\hline & & 14 & Borborygmus & & Constipation subscale (items $18,21,23$ ) \\
\hline & & 15 & Abdominal distension & & Dumping subscale (items $30,31,33$ ) \\
\hline & & 16 & Nausea and vomiting & & \\
\hline & & 17 & Increased flatus & & $\begin{array}{l}\text { Total symptom scale (above seven } \\
\text { subscales) }\end{array}$ \\
\hline & & 18 & Decreased passage of stools & & \\
\hline & & 19 & Increased passage of stools & & \\
\hline & & 20 & Loose stools & & \\
\hline & & 21 & Hard stools & & \\
\hline & & 22 & Urgent need for defecation & & \\
\hline & & 23 & Feeling of incomplete evacuation & & \\
\hline & \multirow{10}{*}{$\begin{array}{l}\text { PGSAS- } \\
\text { specific items }\end{array}$} & 24 & Bile regurgitation & & \\
\hline & & 25 & Sense of foods sticking & & \\
\hline & & 26 & Postprandial fullness & & \\
\hline & & 27 & Early satiation & & \\
\hline & & 28 & Lower abdominal pains & & \\
\hline & & 29 & $\begin{array}{l}\text { Number and type of early dumping } \\
\text { symptoms }\end{array}$ & & \\
\hline & & 30 & Early dumping, general symptoms & & \\
\hline & & 31 & Early dumping, abdominal symptoms & & \\
\hline & & 32 & $\begin{array}{l}\text { Number and type of late dumping } \\
\text { symptoms }\end{array}$ & & \\
\hline & & 33 & Late dumping symptoms & & \\
\hline \multirow[t]{9}{*}{ Living status } & \multirow[t]{4}{*}{ Meals (amount) 1} & 34 & Ingested amount of food per meal* & & - \\
\hline & & 35 & Ingested amount of food per day* & & \\
\hline & & 36 & Frequency of main meals & & \\
\hline & & 37 & Frequency of additional meals & & \\
\hline & \multirow[t]{3}{*}{ Meals (quality) } & 38 & Appetite* & $\begin{array}{l}\text { Five-point Likert } \\
\text { scale }\end{array}$ & $\begin{array}{l}\text { Quality of ingestion subscale* (items } \\
38-40 \text { ) }\end{array}$ \\
\hline & & 39 & Hunger feeling* & & \\
\hline & & 40 & Satiety feeling* & & \\
\hline & Meals (amount) 2 & 41 & Necessity for additional meals & & - \\
\hline & Social activity & 42 & Ability for working & & - \\
\hline \multirow[t]{3}{*}{$\begin{array}{l}\text { Quality of life } \\
\text { (QOL) }\end{array}$} & \multirow[t]{3}{*}{ Dissatisfaction } & 43 & Dissatisfaction with symptoms & & $\begin{array}{l}\text { Dissatisfaction for daily life subscale } \\
\text { (items } 43-45 \text { ) }\end{array}$ \\
\hline & & 44 & Dissatisfaction at the meal & & \\
\hline & & 45 & Dissatisfaction at working & & \\
\hline
\end{tabular}

In items or subscales with $*$, higher score indicates better condition

In items or subscales without *, higher score indicates worse condition

Each subscale is calculated as the mean of composed items or subscales except physical component summary and mental component summary of SF- 8 Items 29 and 32 do not have a score. Thus, they were analyzed separately 
Table 2 Outcome measures in PGSAS (patients after conventional gastrectomy: $N=1,777$ )

\begin{tabular}{|c|c|c|c|c|}
\hline Domain & Item number (\#) & Main outcome measures & Mean & $\mathrm{SD}$ \\
\hline \multirow[t]{8}{*}{ Symptoms } & $10,11,13,24$ & Esophageal reflux subscale & 1.71 & 0.85 \\
\hline & $9,12,28$ & Abdominal pain subscale & 1.70 & 0.77 \\
\hline & $25-27$ & Meal-related distress subscale & 2.19 & 0.96 \\
\hline & $14-17$ & Indigestion subscale & 2.07 & 0.87 \\
\hline & $19,20,22$ & Diarrhea subscale & 2.14 & 1.11 \\
\hline & $18,21,23$ & Constipation subscale & 2.17 & 1.01 \\
\hline & $30,31,33$ & Dumping subscale & 2.04 & 1.04 \\
\hline & $9-28,30,31,33$ & Total symptom score & 2.00 & 0.70 \\
\hline \multirow[t]{5}{*}{ Living status } & - & Change in body weight $(\%)^{*}$ & -9.5 & 8.0 \\
\hline & 34 & Ingested amount of food per meal* & 7.00 & 1.97 \\
\hline & 41 & Necessity for additional meals & 1.98 & 0.81 \\
\hline & $38-40$ & Quality of ingestion subscale* & 3.78 & 0.92 \\
\hline & 42 & Ability for working & 1.84 & 0.88 \\
\hline \multirow[t]{6}{*}{ QOL } & 43 & Dissatisfaction with symptoms & 1.87 & 0.95 \\
\hline & 44 & Dissatisfaction at the meal & 2.32 & 1.13 \\
\hline & 45 & Dissatisfaction at working & 1.79 & 0.97 \\
\hline & $43-45$ & Dissatisfaction for daily life subscale & 2.00 & 0.87 \\
\hline & $1-8$ & Physical component summary* & 50.4 & 5.6 \\
\hline & $1-8$ & Mental component summary* & 49.7 & 5.8 \\
\hline Domain & Item number (\#) & Other outcome measures (symptom) & Mean & $\mathrm{SD}$ \\
\hline \multirow[t]{23}{*}{ Symptoms } & 9 & Abdominal pains & 1.74 & 0.96 \\
\hline & 10 & Heartburn & 1.76 & 1.02 \\
\hline & 11 & Acid regurgitation & 1.81 & 1.12 \\
\hline & 12 & Sucking sensations in the epigastrium & 1.50 & 0.82 \\
\hline & 13 & Nausea and vomiting & 1.50 & 0.94 \\
\hline & 14 & Borborygmus & 1.87 & 1.06 \\
\hline & 15 & Abdominal distension & 2.00 & 1.12 \\
\hline & 16 & Eructation & 1.70 & 0.97 \\
\hline & 17 & Increased flatus & 2.72 & 1.43 \\
\hline & 18 & Decreased passage of stools & 2.13 & 1.25 \\
\hline & 19 & Increased passage of stools & 2.13 & 1.29 \\
\hline & 20 & Loose stools & 2.10 & 1.18 \\
\hline & 21 & Hard stools & 1.96 & 1.12 \\
\hline & 22 & Urgent need for defecation & 2.19 & 1.30 \\
\hline & 23 & Feeling of incomplete evacuation & 2.43 & 1.16 \\
\hline & 24 & Bile regurgitation & 1.77 & 1.07 \\
\hline & 25 & Sense of foods sticking & 1.79 & 1.08 \\
\hline & 26 & Postprandial fullness & 2.39 & 1.21 \\
\hline & 27 & Early satiation & 2.41 & 1.21 \\
\hline & 28 & Lower abdominal pains & 1.87 & 1.11 \\
\hline & 30 & Early dumping general symptoms & 1.96 & 1.20 \\
\hline & 31 & Early dumping abdominal symptoms & 2.34 & 1.31 \\
\hline & 33 & Late dumping symptoms & 1.81 & 1.17 \\
\hline
\end{tabular}


Table 2 continued

\begin{tabular}{lllr}
\hline Domain & Item number (\#) & Other outcome measures (dumping) & Mean \\
\hline Symptoms & 29 & Existence of early dumping general symptoms [Y/N] & 915 \\
& 29 & Existence of early dumping abdominal symptoms [Y/N] & 1,175 \\
& 29 & Existence of either early dumping symptoms [Y/N] & 1,293 \\
& 32 & Existence of late dumping symptoms [Y/N] & 715 \\
& 29 & Number of early dumping general symptoms & 424 \\
& 29 & Number of early dumping abdominal symptoms & 891 \\
& 29 & Number of any early dumping symptoms & 1.95 \\
& 32 & Number of late dumping symptoms & 1.94 \\
& Item number (\#) & Other outcome measures (meals) & 2.87 \\
\hline Domain & 35 & Ingested amount of food per day* & 2.04 \\
\hline \multirow{2}{*}{ Living status } & 36,37 & Frequency of daily meals & 1.85 \\
& 38 & Appetite* & Mean \\
& 39 & Hunger feeling* & 7.24 \\
& 40 & Satiety feeling* & 4.02 \\
& & & 1.99 \\
\end{tabular}

In items or subscales with $*$, higher score indicates better condition

In items or subscales without *, higher score indicates worse condition

have characteristics in common were aggregated. The item pool was further reduced by excluding items that were considered to represent symptoms with a low incidence or are not definitely related to the PGS. To speed up the process of compiling a valid scale, a decision was made to include items from relevant and internationally acclaimed questionnaires. All items from Short Form-8 Health (SF-8) and Gastrointestinal Symptom Rating Scale (GSRS) surveys were subsequently selected for inclusion with permissions from relevant organizations for this study. Thus, PGSAS-45 was established in April 2009.

Structure of the PGSAS-45 (Tables 1, 2; Fig. 1)

PGSAS-45, the end product of the current project with 45 items, became a HRQOL instrument with multidimensional structure consisting of three domains: symptom domain, living status domain, and QOL domain, each consisting of several subdomains (Tables 1, 2; Fig. 1). Twenty-two of the items that had originally been proposed by the JPGSWP members were selected to be retained and added to all 8 items from SF-8 (items 1-8) and all 15 items from GSRS (items 9-23) to constitute the PGSAS-45.

As a symptom domain, 10 original items proposed by the JPGSWP members (items 24-33) were added to the 15 items from GSRS. Of these 10 items, 8 items inquire intensity of symptoms that are actually observed as PGS but had not been evaluated by the conventional questionnaires. The other 2 items (items 29 and 32) inquire whether the patients suffer from early or late dumping syndrome, and the number and types of symptoms if they do. The living status domain consists entirely of the original items proposed by the JPGSWP members and can be stratified into three subdomains (Table 1; Fig. 1). Items 34-37 and 41 constitute the subdomain for the amount of food ingested, and items 38-40 constitute the subdomain for quality of food intake. A subdomain for social activity consists of a single item (item 42). The QOL domain consists of all 8 items from the SF- 8 and 3 original items proposed by the JPGSWP members. These 3 items focused on the issue of dissatisfaction in everyday life caused by symptoms (item 43), feeding problems (item 44), and impaired social activity (item 45), and constitute the dissatisfaction subdomain (Table 1; Fig. 1). Twenty-three of the 25 items in the symptom domain (items 29 and 32 excepted) inquire about intensity of symptoms and are rated on a 7-point Likert scale. One of the 5 items of the amount of food ingested subdomain, all 3 items of the quality of food intake subdomain, the single item for social activity subdomain, and all 3 items of the dissatisfaction subdomain were rated on a 5 -point Likert scale (Table 1). High scores denote favorable outcome in items 1-8 and items 34, 35, and 38-40, whereas low scores indicate superior outcome in items 9-28, 30, 31, 33, and 41-45.

PGSAS (PGS assessment) study, a multi-institutional cross-sectional study

A multi-institutional cross-sectional study involving 52 institutions ( 25 university hospitals, 8 cancer centers, and 19 community hospitals) was conducted by the JPGSWP to assess the patient-reported outcome using the PGSAS-45 


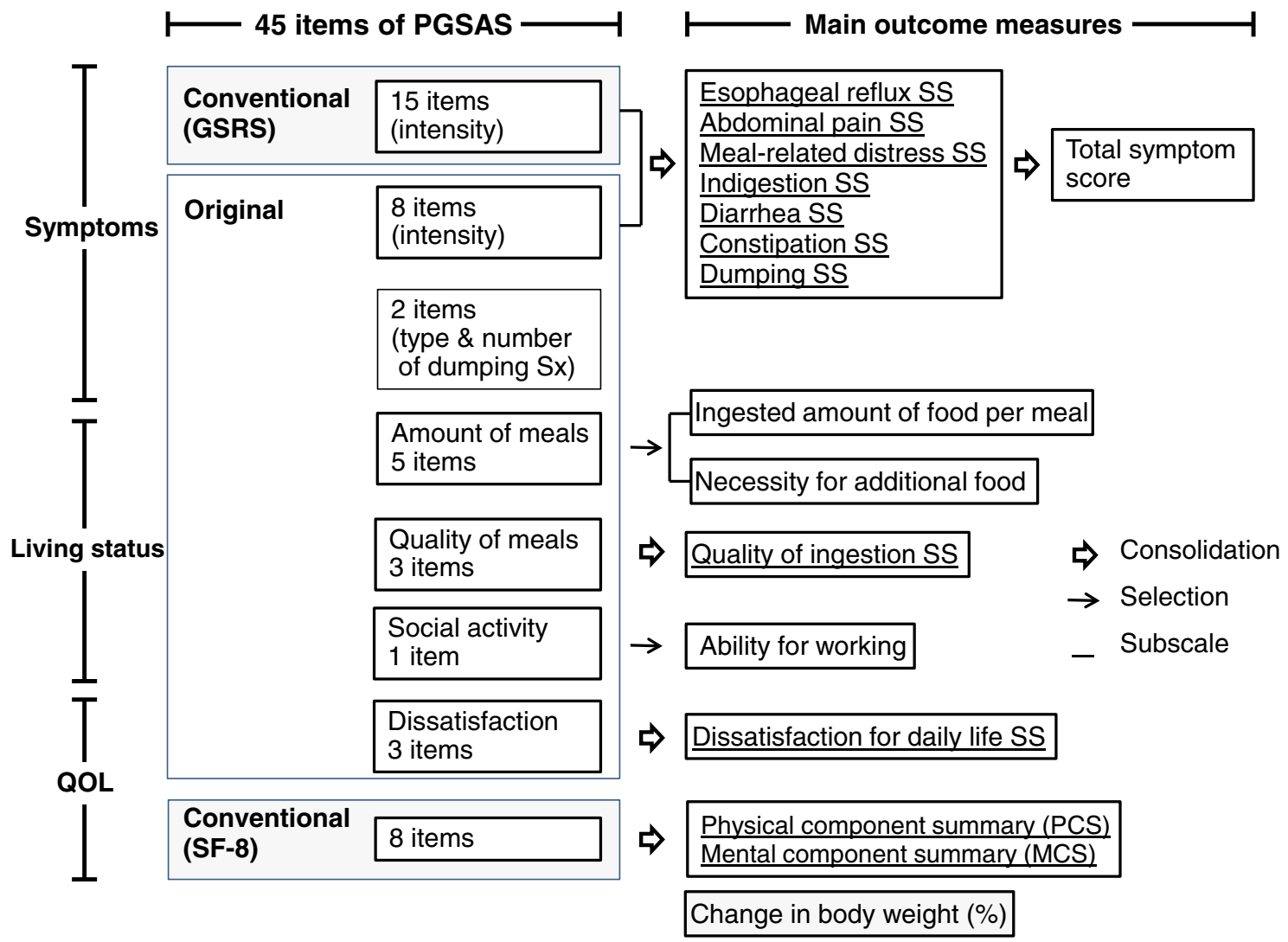

Fig. 1 The process of consolidation and selection to constitute main outcome measures

and to validate this instrument. This study was approved by the institutional review committee (IRB) of Jikei University and subsequently by the IRBs of all participating institutions.

Patients who underwent surgery for gastric cancer and were confirmed pathologically to have stage I disease were eligible. In addition, the patient had to be between 20 and 75 years of age, have undergone no chemotherapy, have lived for more than 1 year after surgery, have no signs of recurrence at the point of assessment, and be without active cancer in other sites. Consecutive sampling of the eligible patients in the outpatient clinic was conducted after obtaining written informed consent. The patients were given the questionnaire sheets together with a stamped and addressed envelope and were asked to fill in the answers and post the sheets to the data cancer. In addition, data regarding background of the patients such as age, gender, height, body weight before surgery and at the time of assessment, time interval since the surgery, the extent of lymphadenectomy (D-number), surgical approach, and details of the surgery performed were retrieved from the medical records and sent to the data center by the medical staff.

Of the 2,922 patients who were handed the questionnaire sheets between July 2009 and December 2010, 2,520 (86 \%) responded and 2,368 were confirmed to be eligible for the

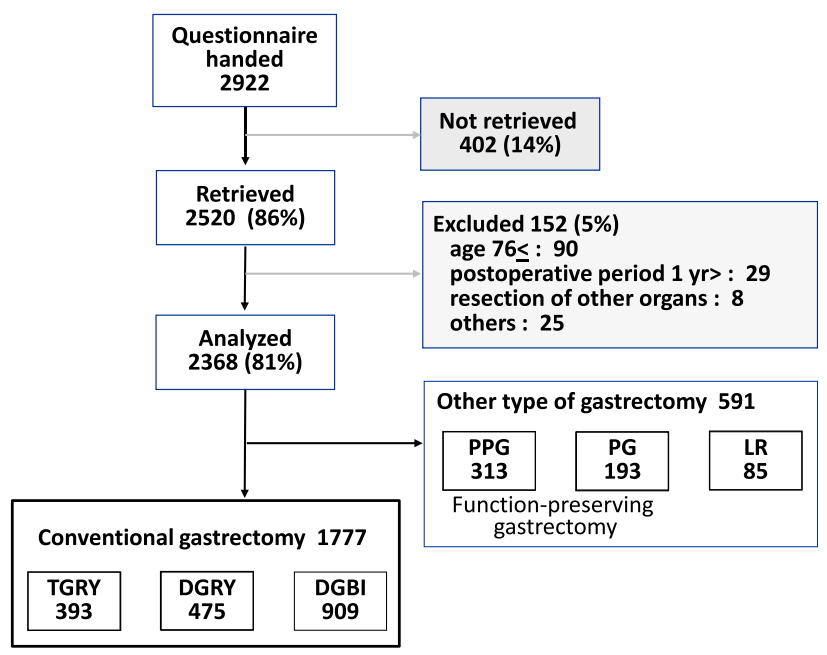

Fig. 2 Outline of the study

study. Of these, data from 1,777 patients who underwent either total or distal gastrectomy were used in the current study to assess construct validity for the PGSAS-45 (Fig. 2). Using these data, we explored relevance of the eight original items proposed by the JPGSWP members that were selected and added to the items derived from the GSRS to constitute the symptom domain of the PGSAS-45. 
In addition to validation of the PGSAS-45, we intended to evaluate the PGS of patients who underwent radical gastrectomy for gastric cancer, and to what extent the symptoms influence the patients' living status or QOL.

\section{Statistical analyses}

Statistical analyses were performed by the biostatisticians mainly using StatView for Windows Ver. 5.0 (SAS Institute, Cary, NC, USA).

Bivariate and multivariate regression analyses were performed to evaluate correlations between the sum of scores for the 15 symptom-related items derived from GSRS or the 8 symptom-related items proposed by the JPGSWP members and scores related to living status and QOL. Factor analysis was used to decide which of the 23 symptom-related items should be clustered to form each symptom subscale. Cronbach's $\alpha$ was calculated from the pairwise correlations between items to verify the internal consistency of the items in each subscale. Correlations between the scores for each of the 7 symptom subscales were calculated in terms of Pearson's $r$, where effect size is considered to be large when $r>0.5$.

\section{Results}

Characteristics and living status of the patients after conventional gastrectomy

Of the 1,777 patients, $1,188(66.9 \%)$ were male; the patients had a mean age of $62.1 \pm 9.2$ years. Of the patients, 393 underwent total gastrectomy, 909 underwent distal gastrectomy with Billroth type I reconstruction, and 475 underwent distal gastrectomy with Roux-en-Y reconstruction. The mean time interval between surgery and retrieval of the questionnaires was $37 \pm 27$ months. Table 2 summarizes the mean values and standard deviation of the main outcome measures and other items evaluated in the PGSAS study. The mean values of the symptom subscales indicate that the symptoms that adversely affect patient well-being are, in the order of importance, meal-related distress, constipation, diarrhea, indigestion, dumping, esophageal reflux, and abdominal pain. The mean loss of body weight at the time the patients were evaluated was $9.5 \pm 8.0 \%$. The amount of food consumed per meal was approximately $70 \%$ of the amount ingested before surgery, and the mean number of meals per day was five. Patient dissatisfaction with life was more closely related to meals rather than their symptoms or their jobs. In contrast, physical and mental components as evaluated by SF-8 were not seriously affected because both scores were around 50 by norm-based scoring.
Factor structure after weighting 23 symptom-related items of the PGSAS-45

Related items were clustered into a subscale to allow more simplified evaluation with a smaller number of scores when necessary. Items 1-8 derived from the SF-8 constitute the physical component summary (PCS) and the mental component summary (MCS). Items 38-40 constitute the quality of ingestion subscale and items 43-45 constitute the dissatisfaction for daily life subscale.

Similarly, the 23 symptom-related items of the PGSAS45, which are rated on a 7-point Likert scale, were clustered into subscales, each consisting of 3-4 related items (GSRS actually has five symptom subscales). For this purpose, factor analysis using the principal factor method with Promax rotation was performed for the observed responses to the 23 symptom-related items of the PGSAS45 (Table 3). Consequently, the 23 items were stratified into seven subgroups in which factor loading took maximal values for all the items and sufficiently large values of 0.7 or higher for most of the items. Thus, factor analysis identified seven clinically relevant subscales, which were named from their content as follows: esophageal reflux subscale (items 10, 11, 13, 24), abdominal pain subscale (items 9, 12, 28), meal-related distress subscale (items 25-27), indigestion subscale (items 14-17), diarrhea subscale (items 19, 20, 22), constipation subscale (items 18, 21, 23), and dumping subscale (items 30, 31, 33). Five of these seven subscales were named the same way as the subgroups of the GSRS, which are termed syndromes, of which three subscales (indigestion, diarrhea, and constipation) had similar content with the corresponding syndromes whereas two other subscales (esophageal reflux and abdominal pain) were dissimilar.

All these seven subscales could further be aggregated as a total symptom score, which is calculated as a mean value of the seven symptom subscales.

\section{Clinical relevance of the eight additional items} proposed by the JPGSWP members

The 8 symptom-related JPGSWP items, rated on a 7-point Likert scale, were compared with the 15 items derived from GSRS in terms of the correlation between the sum of these scores and the scores of the items reflecting either the living status, QOL, or change in body weight. The standardized partial regression coefficients $(\beta)$ took larger values for the JPGSWP items in almost the items reflecting either the living status or QOL, with the exception of the MCS. The $R^{2}$ values of the JPGSWP items as evaluated by bivariate regression analysis were larger than that of the GSRS items across all outcome measures assessing living status and QOL and were 
Table 3 Factor structures in the 23 symptom items of PGSAS-45

\begin{tabular}{|c|c|c|c|c|c|c|c|c|c|}
\hline \multirow[t]{2}{*}{ Factor and item } & \multirow[t]{2}{*}{ Mean } & \multirow[t]{2}{*}{ SD } & \multicolumn{7}{|c|}{ Factor loading } \\
\hline & & & I & II & III & IV & $\mathrm{V}$ & VI & VII \\
\hline \multicolumn{10}{|l|}{ I. Esophageal reflux subscale } \\
\hline Acid regurgitation & 1.81 & 1.12 & 0.968 & -0.031 & -0.059 & -0.005 & 0.013 & -0.020 & -0.065 \\
\hline Bile regurgitation & 1.77 & 1.07 & 0.932 & -0.094 & -0.127 & 0.048 & -0.001 & 0.018 & 0.020 \\
\hline Heartburn & 1.75 & 1.01 & 0.638 & 0.236 & 0.091 & 0.004 & -0.048 & -0.025 & -0.067 \\
\hline Nausea and vomiting & 1.49 & 0.93 & 0.617 & -0.039 & 0.222 & -0.144 & 0.049 & 0.029 & 0.091 \\
\hline \multicolumn{10}{|l|}{ II. Abdominal pain subscale } \\
\hline Sucking sensations in the epigastrium & 1.49 & 0.82 & 0.231 & 0.782 & -0.309 & -0.006 & 0.000 & 0.047 & 0.042 \\
\hline Abdominal pains & 1.74 & 0.96 & 0.049 & 0.781 & 0.176 & -0.052 & 0.001 & -0.042 & -0.024 \\
\hline Lower abdominal pains & 1.87 & 1.11 & -0.258 & 0.547 & 0.322 & 0.025 & 0.117 & 0.108 & 0.070 \\
\hline \multicolumn{10}{|l|}{ III. Meal-related distress subscale } \\
\hline Postprandial fullness & 2.39 & 1.21 & 0.051 & 0.004 & 0.786 & 0.019 & -0.030 & 0.021 & 0.081 \\
\hline Early satiation & 2.41 & 1.21 & 0.019 & -0.002 & 0.738 & 0.006 & -0.009 & 0.073 & 0.089 \\
\hline Sense of foods sticking & 1.79 & 1.07 & 0.388 & -0.259 & $\mathbf{0 . 5 5 0}$ & -0.026 & 0.000 & -0.019 & 0.160 \\
\hline \multicolumn{10}{|l|}{ IV. Indigestion subscale } \\
\hline Increased flatus & 2.72 & 1.43 & -0.098 & -0.245 & -0.118 & 0.880 & 0.110 & 0.108 & 0.080 \\
\hline Borborygmus & 1.87 & 1.06 & 0.056 & 0.107 & -0.065 & 0.723 & 0.050 & -0.135 & 0.084 \\
\hline Abdominal distension & 1.99 & 1.12 & 0.008 & 0.138 & 0.174 & 0.675 & -0.049 & 0.034 & -0.067 \\
\hline Eructation & 1.70 & 0.97 & 0.211 & 0.141 & 0.197 & 0.546 & -0.121 & -0.001 & -0.210 \\
\hline \multicolumn{10}{|l|}{ V. Diarrhea subscale } \\
\hline Increased passage of stools & 2.13 & 1.29 & -0.004 & 0.035 & -0.072 & 0.003 & 0.957 & -0.045 & -0.030 \\
\hline Loose stools & 2.10 & 1.18 & 0.009 & 0.032 & -0.034 & -0.018 & 0.940 & -0.027 & -0.054 \\
\hline Urgent need for defecation & 2.19 & 1.30 & 0.039 & -0.064 & -0.030 & -0.040 & 0.895 & 0.008 & 0.019 \\
\hline \multicolumn{10}{|l|}{ VI. Constipation subscale } \\
\hline Decreased passage of stools & 2.12 & 1.25 & -0.001 & 0.029 & -0.043 & -0.029 & -0.068 & 0.956 & -0.016 \\
\hline Hard stools & 1.96 & 1.12 & 0.017 & 0.027 & -0.012 & -0.058 & -0.113 & 0.942 & -0.021 \\
\hline Feeling of incomplete evacuation & 2.42 & 1.16 & -0.037 & -0.125 & 0.099 & 0.099 & 0.301 & 0.667 & -0.039 \\
\hline \multicolumn{10}{|l|}{ VII. Dumping subscale } \\
\hline Late dumping symptoms & 1.81 & 1.17 & 0.005 & 0.020 & 0.001 & 0.048 & -0.053 & 0.006 & $\mathbf{0 . 8 3 7}$ \\
\hline Early dumping general symptoms & 1.99 & 1.21 & -0.001 & -0.031 & 0.289 & -0.057 & 0.047 & -0.053 & 0.778 \\
\hline Early dumping abdominal symptoms & 2.32 & 1.31 & -0.124 & 0.112 & 0.369 & 0.067 & 0.248 & 0.004 & 0.391 \\
\hline
\end{tabular}

Extraction method: principal factor method with Promax rotation

Maximum value of factor loading for each item was expressed as bold fonts

almost equivalent to $R^{2}$ values evaluated by multivariate analysis (Table 4). These facts indicate that the symptoms asked in the JPGSWP items were significantly more associated with the well-being of the patients than the GSRS items.

Internal consistency of items in each subscale of the PGSAS- 45

In addition to the seven symptom-related subscales, two additional subscales have been proposed: a subscale showing quality of food intake and a subscale showing dissatisfaction in daily life. Internal consistency of the items in each of the nine subscales was acceptable, as shown by the Cronbach's $\alpha$, ranging from 0.65 to 0.88 (Table 5).

Interrelationship between symptom subscales

Correlations between the scores for each symptom subscale are summarized in Table 6. Significant interrelationship $(r>0.5)$ was observed between five subscales-esophageal reflux, abdominal pain, meal-related distress, indigestion, and dumping-whereas the interrelationship between these and two remaining subscales, diarrhea and constipation, were relatively weak $(r>0.3)$. 
Table 4 Significance of added 8 symptoms to 15 symptoms of GSRS for evaluating living status and QOL in the gastrectomized patients

\begin{tabular}{|c|c|c|c|c|c|c|c|c|c|c|c|c|}
\hline & \multicolumn{6}{|c|}{ Simple linear regression analysis } & \multicolumn{6}{|c|}{ Multiple linear regression analysis } \\
\hline & \multicolumn{3}{|c|}{$\begin{array}{l}\text { Sum of GSRS Sx } \\
\text { (15) }\end{array}$} & \multicolumn{3}{|c|}{$\begin{array}{l}\text { Sum of added Sx } \\
\text { (8) }\end{array}$} & \multicolumn{2}{|c|}{$\begin{array}{l}\text { Sum of GSRS Sx } \\
\text { (15) }\end{array}$} & \multicolumn{2}{|c|}{$\begin{array}{l}\text { Sum of added Sx } \\
(8)\end{array}$} & \multirow[b]{2}{*}{$R^{2}$} & \multirow[b]{2}{*}{$p$ value } \\
\hline & $b$ & $p$ value & $R^{2}$ & $b$ & $p$ value & $R^{2}$ & $\beta$ & $p$ value & $\beta$ & $p$ value & & \\
\hline Change in body weight $(\%)^{*}$ & -0.117 & $<0.0001$ & $(0.014)$ & -0.181 & $<0.0001$ & 0.033 & $(0.074)$ & 0.0851 & -0.240 & $<0.0001$ & 0.035 & $<0.0001$ \\
\hline $\begin{array}{l}\text { Ingested amount of food per } \\
\text { meal* }\end{array}$ & -0.277 & $<0.0001$ & 0.077 & -0.340 & $<0.0001$ & 0.116 & $(-0.020)$ & $\geq 0.1$ & -0.324 & $<0.0001$ & 0.116 & $<0.0001$ \\
\hline Necessity for additional meals & 0.288 & $<0.0001$ & 0.083 & 0.365 & $<0.0001$ & 0.133 & $(-0.004)$ & $\geq 0.1$ & 0.368 & $<0.0001$ & 0.133 & $<0.0001$ \\
\hline Ability for working & 0.369 & $<0.0001$ & 0.137 & 0.424 & $<0.0001$ & 0.180 & $(0.091)$ & 0.0196 & 0.353 & $<0.0001$ & 0.183 & $<0.0001$ \\
\hline $\begin{array}{l}\text { Dissatisfaction with } \\
\text { symptoms }\end{array}$ & 0.533 & $<0.0001$ & 0.284 & 0.613 & $<0.0001$ & 0.375 & 0.127 & 0.0002 & 0.512 & $<0.0001$ & 0.381 & $<0.0001$ \\
\hline Dissatisfaction at the meal & 0.480 & $<0.0001$ & 0.230 & 0.580 & $<0.0001$ & 0.336 & $(0.054)$ & $\geq 0.1$ & 0.537 & $<0.0001$ & 0.338 & $<0.0001$ \\
\hline Dissatisfaction at working & 0.475 & $<0.0001$ & 0.226 & 0.553 & $<0.0001$ & 0.306 & $(0.098)$ & 0.0058 & 0.476 & $<0.0001$ & 0.310 & $<0.0001$ \\
\hline $\begin{array}{l}\text { Dissatisfaction for daily life } \\
\text { subscale }\end{array}$ & 0.579 & $<0.0001$ & $\mathbf{0 . 3 3 5}$ & 0.682 & $<0.0001$ & 0.464 & 0.105 & 0.0007 & 0.598 & $<0.0001$ & 0.469 & $<0.0001$ \\
\hline $\begin{array}{l}\text { Physical component } \\
\text { summary* }\end{array}$ & -0.443 & $<0.0001$ & 0.196 & -0.481 & $<0.0001$ & 0.231 & -0.166 & $<0.0001$ & -0.349 & $<0.0001$ & 0.241 & $<0.0001$ \\
\hline Mental component summary* & -0.458 & $<0.0001$ & 0.210 & -0.461 & $<0.0001$ & 0.212 & -0.249 & $<0.0001$ & -0.269 & $<0.0001$ & 0.235 & $<0.0001$ \\
\hline Interpretation of effect size & $b, \beta$ & $R^{2}$ & & & & & & & & & & \\
\hline None-very small & $<(0.100)$ & $<(0.020)$ & & & & & & & & & & \\
\hline Small & $\geq 0.100$ & $\geq 0.020$ & & & & & & & & & & \\
\hline Medium & $\geq 0.300$ & $\geq 0.130$ & & & & & & & & & & \\
\hline Large & $\geq \mathbf{0 . 5 0 0}$ & $\geq 0.260$ & & & & & & & & & & \\
\hline
\end{tabular}

In items or subscales with *, higher score indicating better condition. In items or subscales without *, higher score indicating worse condition

The fonts of values of $b, \beta$ or $R^{2}$ were varied according to their effect size; 'None-very small' as parenthetic, 'Small' as normal fonts, 'Medium' as italic fonts and 'Large' as bold fonts

Table 5 Internal consistency of each subscale of the PGSAS-45

\begin{tabular}{ll}
\hline Subscales & Cronbach's $\alpha$ \\
\hline Esophageal reflux & 0.83 \\
Abdominal pain & 0.71 \\
Meal-related distress & 0.76 \\
Indigestion & 0.74 \\
Diarrhea & 0.88 \\
Constipation & 0.81 \\
Dumping & 0.80 \\
Quality of ingestion & 0.65 \\
Dissatisfaction for daily life & 0.81 \\
Interpretation of Cronbach's $\alpha$ & \\
Excellent & $0.9 \leq \alpha$ \\
Good & $0.7 \leq \alpha<0.9$ \\
Acceptable & $0.6 \leq \alpha<0.7$ \\
Poor & $0.5 \leq \alpha<0.6$ \\
Unacceptable & $\alpha<0.5$ \\
\hline
\end{tabular}

Main outcome measures and other outcome measures in the PGSAS study (Table 2)

After the validation process, data obtained by the PGSAS study will undergo subsequent analyses, mainly comparisons between different surgical procedures, and the results will be published in due time. For use in these analyses, main outcome measures were determined.

Seven symptoms subscales, total symptom score, a subscale showing quality of feeding, a subscale showing dissatisfaction in life, PCS, and MCS were selected as main outcome measures in the future analyses. In addition, the amount of food per meal occasion (item 34) and necessity of an additional meal (item 41) were added as single items because they correlated well with the ability to work (item 42) and various QOL measures such as PCS, MCS, and dissatisfaction for daily life subscale (data not shown). Dissatisfaction with the symptoms, dissatisfaction at the meal, and dissatisfaction during work (items 43-45) were also added as single items to see how these affected QOL of the postgastrectomy patients. Apart from the scores derived from PGSAS-45, body weight loss (percentage of body weight loss in relationship to preoperative weight) as obtained from the medical record was added as the main outcome measures.

\section{Discussion}

After gastrectomy, patients suffer from various illnesses and functional problems comprehensively referred to as 
Table 6 Inter-factor correlations among symptom subscales of the PGSAS-45

\begin{tabular}{|c|c|c|c|c|c|c|c|}
\hline Subscale & I & II & III & IV & $\mathrm{V}$ & VI & VII \\
\hline I. Esophageal reflux & 1.000 & & & & & & \\
\hline II. Abdominal pain & 0.590 & 1.000 & & & & & \\
\hline III. Meal-related distress & 0.598 & 0.608 & 1.000 & & & & \\
\hline IV. Indigestion & 0.545 & 0.549 & 0.584 & 1.000 & & & \\
\hline V. Diarrhea & 0.276 & 0.374 & 0.364 & 0.450 & 1.000 & & \\
\hline VI. Constipation & 0.391 & 0.445 & 0.447 & 0.454 & 0.274 & 1.000 & \\
\hline VII. Dumping & 0.514 & 0.607 & 0.640 & 0.575 & 0.467 & 0.391 & 1.000 \\
\hline Interpretation of effect size & $r$ & & & & & & \\
\hline Small & $\geq 0.100$ & & & & & & \\
\hline Medium & $\geq 0.300$ & & & & & & \\
\hline Large & $\geq 0.500$ & & & & & & \\
\hline
\end{tabular}

The fonts of values of $r$ were varied according to their effect size; 'Small' as normal fonts, 'Medium' as italic fonts and 'Large' as bold fonts

PGS [1-6]. Although the primary objective of gastrectomy is to cure cancer, the second most important goal is to minimize PGS-related adverse events and to preserve the patients' QOL. This goal is particularly important in the Far East where gastric cancer is often found at early clinical stages so that more patients manage to survive their cancer and consequently need to face the PGS in the long term [9]. It is known that the type of gastrectomy affects the incidence and severity of PGS [10-21], and various procedures to preserve or reconstruct gastric function have been proposed to confront these problems [7, 8]. To gain deeper understanding of the PGS, a group of iatrogenic disorders, and treat them appropriately, it is important to grasp the impact of various symptoms, along with feeding problems and body weight loss, to the living status and QOL of the patients. In addition, identifying the problems and their correlations with various types of surgical procedures may lead to evolution of a novel surgical technique as well as more adequate selection of conventional technique to circumvent the problems. However, instruments designed to focus on the evaluation of PGS have not been established to date.

Patient-reported outcome directly reflects the symptoms and complaints of patients. This type of report is particularly valuable as an endpoint when evaluating QOL after surgery because PGS often is detected only through complaints from the patients [22]. Several studies made comparisons between different surgical procedures to find which procedure is beneficial for the patients from the point of view of PGS, but these comparisons often looked only at specific outcomes that particularly aroused the interest of the investigators [17, 19] and were not necessarily comprehensive and convincing. Moreover, using arbitrary endpoints renders comparisons between different studies impossible. More recently, investigators turned to the established and authorized questionnaires for comparisons between gastric surgery procedures $[10-15$, 18, 20], because there are several combinations of core questionnaires and disease-specific modules that are considered appropriate and have been approved for evaluation of QOL [23, 24]. A combination of SF-36, a core questionnaire, and GSRS, a symptom-specific QOL, has been one of the examples [11, 14], but the GSRS may have a tendency to overlook some of the symptoms that are peculiar to the patients who have undergone gastrectomy and are unusual for other disorders of the gastrointestinal tract. EORTC QLQ-C30 [25], a cancer-specific core questionnaire, and STO-22 [26] is another combination that has been used to evaluate postgastrectomy patients [12, 13]. However, these questionnaires have been developed to evaluate QOL of the patients who are burdened with cancer and are receiving treatments rather than those who became cancer free through surgery but are suffering from PGS.

The investigators who wish to evaluate PGS had thus been obliged to turn to modules designed for other purposes because of the lack of an optimally constructed questionnaire. Therefore, there are possibilities that a large proportion of these studies have overlooked several important postgastrectomy symptoms that actually affect the living status of the patients but cannot be evaluated by conventional scales. More recently, Nakamura et al. reported on DAUGS, a questionnaire designed to measure symptoms after upper gastrointestinal surgery, and the actual attempt to use this in the clinical setting [16, 21]. However, items concerning living status or QOL of the patients rather than the symptoms were lacking in the DAUGS.

PGSAS-45 was constructed through contribution of several expert surgeons with abundant experience coping with postgastrectomy patients as the only comprehensive questionnaire that is suitable for evaluating patients who have undergone various types of gastrectomy and reconstruction. PGSAS-45 is a package with complex structures 
and includes items from multiple dimensions. Its core stems from internationally acclaimed questionnaires in that it contains items from SF-8 [27] and GSRS under the permission of each copyright owner for this study. GSRS has five subscales that are in common with the PGSAS-45 and has been extensively used to evaluate patients with various disorders of the gastrointestinal tract [28, 29]. However, it does not cover some symptoms that are peculiar to postgastrectomy patients such as postprandial satiation and symptoms related to the dumping syndrome. PGSAS-45 was constructed through contributions of several expert surgeons during the comprehensive item generation phase. Inclusion of the 8 additional symptomrelated items that were proposed and selected by the surgeons to evaluate postgastrectomy patients is expected to increase sensitivity to more meticulously detect and evaluate the PGS. Multivariate regression analysis has shown through larger $\beta$ coefficients that the 8 items actually correlated more significantly with most of the subscales looking at the living status and QOL of the patients when compared with the 15 items derived from GSRS. Moreover, the $R^{2}$ values of the JPGSWP items as calculated by the bivariate regression analysis were almost equivalent to $R^{2}$ values of all symptom items calculated by the multivariate analysis, indicating that the 8 items had a decisive role in evaluating the effect of surgery on the living status and QOL of the patients. The relatively large effect size of the total symptoms in the $R^{2}$ value, which was calculated by multivariate analysis, indicates that the symptom has a certain impact on living status and QOL in the postgastrectomy patients (Table 4).

Factor analysis resulted in construction of five subscales that are in common with the GSRS. Two of these subscales actually contained items that are different from the GSRS. In addition, two novel subscales, meal-related distress and dumping, were generated that would apparently result in extra sensitivity to detect symptoms. Two further subscales showing dissatisfaction for daily life and quality of ingestion were added to augment QOL and living status domains. Cronbach's $\alpha$ is a coefficient of internal consistency and is commonly used as an estimate of the reliability. The interpretation of Cronbach's $\alpha$ is shown in Table 5. Acceptable internal consistency was observed in all nine subscales, including the four new subscales.

\section{Conclusions}

In conclusion, we have developed a useful multidimensional integrated quality of life measure, PGSAS-45. This questionnaire benefited from addition of the eight symptom-related items derived from comprehensive item generation process contributed by expert surgeons, and led to generation of two additional subscales: meal-related distress subscale and dumping subscale. It is expected to serve as a gold standard in the evaluation of PGS and provide a meticulous profile of symptoms in postgastrectomy patients. Furthermore, the PGSAS study generated a prospective multi-institutional database of HRQOL assessed by PGSAS- 45 among patients who were treated by the six most frequent types of gastrectomy. Several comparative analyses using these data and main outcome measures as defined in the current study are ongoing, and results are awaited.

Acknowledgments This study was supported by a grant from Jikei University and the Japanese Society for Gastro-surgical Pathophysiology. This study was conducted by JPGSWP and registered to UMIN-CTR \#000002116 entitled as "A study to observe correlation between resection and reconstruction procedures employed for gastric neoplasms and development of postgastrectomy syndrome." The results of this study were presented at Digestive Disease Week 2013, Orland, FL, USA [30]. The authors thank all the physicians who participated in this study and the patients whose cooperation made this study possible.

\section{References}

1. Bolton JS, Conway WC 2nd. Postgastrectomy syndromes. Surg Clin N Am. 2011;91(5):1105-22.

2. Carvajal SH, Mulvihill SJ. Postgastrectomy syndromes: dumping and diarrhea. Gastroenterol Clin N Am. 1994;23(2):261-79.

3. Cooperman AM. Postgastrectomy syndromes. Surg Annu. 1981;13:139-61.

4. Eagon JC, Miedema BW, Kelly KA. Postgastrectomy syndromes. Surg Clin N Am. 1992;72(2):445-65.

5. Harju E. Metabolic problems after gastric surgery. Int Surg. 1990;75(1):27-35.

6. Jay BS, Burrell M. Iatrogenic problems following gastric surgery. Gastrointest Radiol. 1977;2(3):239-57.

7. Katai H. Function-preserving surgery for gastric cancer. Int J Clin Oncol. 2006;11(5):357-66.

8. Lehnert $\mathrm{T}$, Buhl $\mathrm{K}$. Techniques of reconstruction after total gastrectomy for cancer. Br J Surg. 2004;91(5):528-39.

9. Maruyama K, Kaminishi M, Hayashi K, Isobe Y, Honda I, Katai H, et al. Gastric cancer treated in 1991 in Japan: data analysis of nationwide registry. Gastric Cancer. 2006;9(2):51-66.

10. Endo S, Nishida T, Nishikawa $K$, Yumiba T, Nakajima $K$, Yasumasa $\mathrm{K}$, et al. Motility of the pouch correlates with quality of life after total gastrectomy. Surgery (St. Louis). 2006;139(4): 493-500.

11. Hayami M, Seshimo A, Miyake K, Shimizu S, Kameoka S. Effects of emptying function of remaining stomach on QOL in postgastrectomy patients. World J Surg. 2012;36(2):373-8.

12. Huang CC, Lien HH, Wang PC, Yang JC, Cheng CY, Huang CS. Quality of life in disease-free gastric adenocarcinoma survivors: impacts of clinical stages and reconstructive surgical procedures. Dig Surg. 2007;24(1):59-65.

13. Kobayashi D, Kodera Y, Fujiwara M, Koike M, Nakayama G, Nakao A. Assessment of quality of life after gastrectomy using EORTC QLQ-C30 and STO22. World J Surg. 2011;35(2): 357-64.

14. Kono K, Iizuka H, Sekikawa T, Sugai H, Takahashi A, Fujii H, et al. Improved quality of life with jejunal pouch reconstruction after total gastrectomy. Am J Surg. 2003;185(2):150-4. 
15. Lee MS, Ahn SH, Lee JH, Park do J, Lee HJ, Kim HH, et al. What is the best reconstruction method after distal gastrectomy for gastric cancer? Surg Endosc. 2012;26(6):1539-47.

16. Nakamura M, Kido Y, Yano M, Hosoya Y. Reliability and validity of a new scale to assess postoperative dysfunction after resection of upper gastrointestinal carcinoma. Surg Today. 2005;35(7):535-42.

17. Nakane $Y$, Michiura $T$, Inoue $K$, Iiyama $H$, Okumura S, Yamamichi $\mathrm{K}$, et al. A randomized clinical trial of pouch reconstruction after total gastrectomy for cancer: which is the better technique, Roux-en-Y or interposition? Hepatogastroenterology. 2001;48(39):903-7.

18. Namikawa T, Kitagawa H, Okabayashi T, Sugimoto T, Kobayashi M, Hanazaki K. Roux-en-Y reconstruction is superior to Billroth I reconstruction in reducing reflux esophagitis after distal gastrectomy: special relationship with the angle of His. World $\mathbf{J}$ Surg. 2010;34(5):1022-7.

19. Nunobe S, Okaro A, Sasako M, Saka M, Fukagawa T, Katai H, et al. Billroth 1 versus Roux-en-Y reconstructions: a quality-oflife survey at 5 years. Int J Clin Oncol. 2007;12(6):433-9.

20. Svedlund J, Sullivan M, Liedman B, Lundell L, Sjodin I. Quality of life after gastrectomy for gastric carcinoma: controlled study of reconstructive procedures. World J Surg. 1997;21(4):422-33.

21. Takiguchi S, Yamamoto K, Hirao M, Imamura H, Fujita J, Yano $\mathrm{M}$, et al. A comparison of postoperative quality of life and dysfunction after Billroth I and Roux-en-Y reconstruction following distal gastrectomy for gastric cancer: results from a multi-institutional RCT. Gastric Cancer. 2012;15(2):198-205.

22. Karanicolas PJ, Bickenbach K, Jayaraman S, Pusic AL, Coit DG, Guyatt GH, et al. Measurement and interpretation of patientreported outcomes in surgery: an opportunity for improvement. J Gastrointest Surg. 2011;15(4):682-9.
23. Borgaonkar MR, Irvine EJ. Quality of life measurement in gastrointestinal and liver disorders. Gut. 2000;47(3):444-54.

24. Moyer CA, Fendrick AM. Measuring health-related quality of life in patients with upper gastrointestinal disease. Dig Dis. 1998;16(5):315-24.

25. Aaronson NK, Ahmedzai S, Bergman B, Bullinger M, Cull A, Duez NJ, et al. The European Organization for Research and Treatment of Cancer QLQ-C30: a quality-of-life instrument for use in international clinical trials in oncology. J Natl Cancer Inst. 1993;85(5):365-76.

26. Vickery CW, Blazeby JM, Conroy T, Arraras J, Sezer O, Koller $\mathrm{M}$, et al. Development of an EORTC disease-specific quality of life module for use in patients with gastric cancer. Eur J Cancer. 2001;37(8):966-71.

27. Turner-Bowker DM, Bayliss MS, Ware JE Jr, Kosinski M. Usefulness of the SF-8 Health Survey for comparing the impact of migraine and other conditions. Qual Life Res. 2003;12(8): 1003-12.

28. Svedlund J, Sjodin I, Dotevall G. GSRS-a clinical rating scale for gastrointestinal symptoms in patients with irritable bowel syndrome and peptic ulcer disease. Dig Dis Sci. 1988;33(2): 129-34.

29. Revicki DA, Wood M, Wiklund I, Crawley J. Reliability and validity of the Gastrointestinal Symptom Rating Scale in patients with gastroesophageal reflux disease. Qual Life Res. 1998;7(1): $75-83$.

30. Nakada K, Ikeda M, Takahashi M, Kinami S, Yoshida M, Uenosono Y, et al. Development and validation of PGSAS-45, an integrated questionnaire to assess postgastrectomy syndrome. Gastroenterology. 2013;144(5 suppl 1):S-1111. 